\title{
ATUALIDADES
}

\section{OBSERVAÇÕES SÔBRE A CURA DE CINCO DIAS PELA QUININA NO TRATAMENTO DO PALUDISMO (1)}

\author{
DR. J. P. SANDERS, M. D. \\ Caspiana (Luisiana) - Malariologista do Hospital de Caridade de \\ Shreverport \\ DR. W. T. DAWSON, M. A. \\ Professor de Farmacologia da Escola de Medicina da Universidade \\ de Texas, Galveston (Texas).
}

Com a colaboração de nossos colegas do Hospital de Caridade de Shreveport, foram feitas observações sôbre 189 doentes tratados de paludismo, durante o ano de 1937. Entre aquêles doentes, 65 receberam de $O$ gr. 65 a 1 gr. 30 de quinina por dia, 84 , de 1 gr. 95 a 2 grs. 60 , e 40 , de 3 grs. 60 a 5 grs. 85 (2). A justificativa para dóses tão elevadas desde o inicio, era o objetivo de reduzir a febre o mais rapidamente possivel. Entretanto, nesse grupo de 189 doentes, não foi constatada nenhuma diferença importante nos resultados imediatos obtidos com as três dosagens.

Por outro lado, foram estabelecidas comparações entre o tratamento pela quinidina e o tratamento pela quinina. 1.349 doentes receberam o primeiro alcalóide e apenas 81 o esgundo. Estas experiencias, que tiveram inicio em 1935, foram consideravelmente expandidas no decorrer dos dois ultimos anos. Ficou admitido que cada espécie de plasmódio reage, à sua maneira, em relação ao tratamento. Assim, nas Indias, a quinina mostrou-se muito eficaz na supressão dos acessos devidos ao Pl. Falciparum (terça maligna),, sem dar, no entanto, tão bons resultados contra as raças italianas do mesmo parasito.

Tanto os doentes tratados por meio de curas breves pela quinina, repetidas sempre que se faziam necessarias, como aquêles tratados pela quinidina, só demonstraram a necessidade de um tratamento ulterior pouco importante. Além disso, não se registraram grandes diferenças nos resultados alcançados com dóses quotidianas de $0 \mathrm{gr}$. 65 ou $1 \mathrm{gr}$. 30. Si bem que seja dificil determinar exatamente a percentagem das recaídas, uma vez que os doentes continuaram a residir nas regiões em que contraíram o impaludismo, póde-se, entretanto, considera-la pouco elevada. Póde-se calcular, num ano, de $25 \%$ a $45 \%$, taxa que compreende não apenas os acessos que se produzem no decorrer do ano em que a primeira cura foi administrada, mas tambem os que se produziram no ano seguinte. Esta taxa está ainda provavelmente exagerada, especialmente para os doentes que na ocasião de uma recaída acusavam, no exame de sangue,

(1) Tradução dos comenatrios: OBSERVATIONS SUR LA CURE A LA QUININE DES CINQ JOURS DANS LE TRAITEMENT DU PALADISME.

(2) NOTA: - 1 grão $=0$ gr. 065 - As dóses originais são expressas em grãos. O tradutor, para maior facilidade, e dentro das devidas régras, arredondou as cifras, sempre que despreziveis as frações. 

um resultado negativo ou uma raça de parasitos diferente do agente da infecção
inicial.

Nossa experiencia demonstrou que o tratamento pela quinina ou pela quinidina é muito eficaz contra os parasitos do paludismo existente em redor de Shreveport (Louisiana), e em alguns impaludados hospitálisados no Hospital John Sealy, de Galveston, onde o paludismo não é endemico.

A repetição dos tratamentos rapidos pela quinina é eficaz. Com efeito, os parasitos não se mostram tolerantes, nem quinino-resistentes, nem resistentes ao seu hospedeiro. Que tal resultado seja devido ou não à brevidade dos tratamentos administrados, nunca se poderia precisar. A Comissão de Paludismo da Sociedade das Naçoes declarou, no que concerne ao tratamento pela quinina, qué "máus resultados pódem surgir quando o tratamento e prolongado sem necessidade".

Sôbre 349 doentes atacados de paludismo e que receberam um tratamento ambulante de 1. gr. 30 de quinina (3), diariamente, durante 5 dias, 97 sofriam de terçã benigna, 117 de terçã maligna e 135 apresentaram um exame negativo. Entre os primeiros, 22\% apresentaram durante o mesmo ano uma recaída, e 19\% recaíram no ano seguinte. Entre os segundos, $28 \%$ tiveram no mesmo ano uma recaída e $8 \%$ recaíram no ano seguinte. Quanto aos da terceira categoria, $4 \%$ recaíram no decorrer do mesmo ano e $16 \%$ no ano seguinte. Esses ultimos resultados, que concernem aos doentes que tiveram um exame de sangue negativo e que foram denominados "impaludados clinicos", são muito interessantes, uma vez que o numero de recaídas constatado em tal grupo é bem inferior ao dos outros dois. Isto provavelmente é devido ao esclarecimento do relatorio de BisphaM, segundo o qual os "impaludados clinicos" não tinham paludismo.

\section{CONCLUSÕES}

Os resultados alcançados são, de um modo geral, comparaveis aos observados na Europa, segundo o relatorio de HACKETT.

A pratica da cura de 5 dias pela quinina no tratamento do paludismo em dóses diárias de 0 gr. 65 ou 1 gr. 30 , permite concluir:

$\left.1 .^{\circ}\right)$ A febre é tão prontamente combatida como por dóses mais elevadas;

$2^{\circ}{ }^{\circ}$ A percentagem das recaídas no decorrer do ano, póde ser avaliada entre $25 \%$ a $45 \%$;

3.0) Após reflexão, não se torna possivel comparar um ao outro, o tratamento prolongado e o tratamento rápido, porque nada nos assegura que os doentes submetidos ao primeiro tratamento tivessem realmente continuado a tomar o medicamento.

Não podemos sinão referir-nos às publicações da Comissão de Paludismo da Sociedade das Nações e ao valioso trabalho de Hackett em favor do tratamento rapido, repetido sempre que houver necessidade.

Hackett concluiu de sua experiencia na Sardenha, sôbre 300 doentes não hospitalisados, que a taxa de recaídas dos impaludados submetidos a um tratamento prolongado foi de $40 \%$, e a de impaludados submetidos ao tratamento rapido de $46 \%$. "Isto certamente não valeu o trabalho suplementar e as despesas feitas para convencer os camponezes apaticos a engulir, cada dia, a quinina, durante dois mêses." (Southern Medical Journal, Birmingham, Ala., Julho de 1939). 